\title{
Identification of a novel enhancer that binds Sp1 and contributes to induction of cold-inducible RNA-binding protein (cirp) expression in mammalian cells
}

Yasuhiko Sumitomo 1,2,3, Hiroaki Higashitsuji ${ }^{*}$, Hisako Higashitsuji ${ }^{1}$, Yu Liu', Takanori Fujita', Toshiharu Sakurai ${ }^{4}$, Marco M Candeias ${ }^{1,5}$, Katsuhiko Itoh', Tsutomu Chiba ${ }^{2}$ and Jun Fujita ${ }^{1 *}$

\begin{abstract}
Background: There are a growing number of reports on the sub-physiological temperature culturing of mammalian cells for increased recombinant protein yields. However, the effect varies and the reasons for the enhancement are not fully elucidated. Expression of cold-inducible RNA-binding protein (cirp, also called cirbp or hnRNP A18) is known to be induced in response to mild, but not severe, hypothermia in mammalian cells. To clarify the molecular mechanism underlying the induction and to exploit this to improve the productivity of recombinant proteins, we tried to identify the regulatory sequence(s) in the $5^{\prime}$ flanking region of the mouse cirp gene.

Results: By transiently transfecting HEK293 cells with plasmids expressing chloramphenicol acetyltransferase as a reporter, we found that the cirp $5^{\prime}$ flanking region octanucleotide $5^{\prime}$-TCCCCGCC-3' is a mild-cold responsive element (MCRE). When 3 copies of MCRE were placed upstream of the CMV promoter and used in transient transfection, reporter gene expression was increased 3- to 7 -fold at $32^{\circ} \mathrm{C}$ relative to $37^{\circ} \mathrm{C}$ in various cell lines including HEK293, U-2 OS, NIH/3T3, BALB/3T3 and CHO-K1 cells. In stable transfectants, MCRE also enhanced the reporter gene expression at $32^{\circ} \mathrm{C}$, although more copy numbers of MCRE were necessary. Sp1 transcription factor bound to MCRE in vitro. Immunohistochemistry and chromatin immunoprecipitation assays demonstrated that more Sp1, but not $\mathrm{Sp3}$, was localized in the nucleus to bind to the cirp regulatory region containing MCRE at $32^{\circ} \mathrm{C}$ than $37^{\circ} \mathrm{C}$. Overexpression of Sp1 protein increased the expression of endogenous Cirp as well as a reporter gene driven by the $5^{\prime}$ flanking region of the cirp gene, and down-regulation of Sp1 had the opposite effect. Mutations within the MCRE sequence in the $5^{\prime}$ flanking region abolished the effects of Sp1 on the reporter gene expression both at $37^{\circ} \mathrm{C}$ and $32^{\circ} \mathrm{C}$.
\end{abstract}

Conclusions: Cold-induced, as well as constitutive, expression of cirp is dependent, at least partly, on MCRE and Sp1. The present novel enhancer permits conditional high-level gene expression at moderately low culture temperatures and could be utilized to increase the yield of recombinant proteins in mammalian cells.

Keywords: Cold shock protein, Stress response, Enhancer, Transcription factor, Recombinant protein

\footnotetext{
*Correspondence: hhigashi@virus.kyoto-u.ac.jp; jujita@virus.kyoto-u.ac.jp 'Department of Clinical Molecular Biology, Graduate School of Medicine, Kyoto University, 54 Shogoin Kawaharacho, Sakyo-ku, Kyoto 606-8507, Japan Full list of author information is available at the end of the article
} 


\section{Background}

Cold-inducible RNA-binding protein (Cirp, also called Cirbp or hnRNP A18) is the first cold shock protein identified in mammals [1,2]. Being composed of one consensus sequence-RNA binding domain and a carboxylterminal region containing several arginine glycine glycine motifs, it is structurally quite different from bacterial cold shock proteins. Expression of Cirp is induced in response to mild, but not severe, hypothermia. Cirp is also induced by cellular stresses such as UV irradiation and hypoxia $[3,4]$. Upon stress induction, Cirp shuttles from the nucleus to the cytoplasm, and affects stability and translation of its target mRNAs [5]. Cirp modulates cell cycle progression, protects cells from various stresses, and possibly functions as an oncoprotein [2,6-8]. Cirp is constitutively expressed in a variety of tissues and cells, predominantly in the testis and brain, and contributes to the maintenance of normal cellular functions as well. Recently, we have produced cirp-knockout mice and demonstrated that Cirp stimulates proliferation of undifferentiated spermatogonia by interacting with Dyrk1b/ Mirk protein [9]. The mechanism(s) underlying the induction of cold shock proteins by mild hypothermia has not yet been fully elucidated.

Specificity protein $1(\mathrm{Sp} 1)$ is a member of the large multigene family of $\mathrm{Sp} /$ Kruppel-like factor transcription factors that can activate or repress transcription in response to physiologic and pathologic stimuli [10]. These proteins share a highly conserved DNA binding domain, and through 3 adjacent $\mathrm{C} 2 \mathrm{H} 2$-type zinc fingers at the $\mathrm{C}$-terminus, they bind to GC boxes, CACCC boxes, and basic transcription elements. Sp1 through $\mathrm{Sp} 4$ form a subgroup that contains glutamine-rich transactivating domains. Sp1, Sp3, and Sp4 have 2 such domains, whereas Sp2 has only 1 and exhibits different DNA binding specificity. Sp1 and Sp3 are expressed ubiquitously, whereas $\mathrm{Sp} 4$ is expressed primarily in neural cells. Often in cooperation with other transcription factors, Sp proteins regulate the expression of numerous genes implicated in the control of a diverse array of cellular processes, such as cell growth, differentiation, apoptosis, and angiogenesis [11].

A number of biotechnology products currently marketed are large molecules, produced from genetically modified mammalian cell lines, and extracted through complex and lengthy purification procedures [12,13]. The expiration of patents for expensive protein drugs and the development of monoclonal antibodies as therapeutics have intensified competitive efforts to improve the productivity of recombinant proteins. One area in which there is currently a large volume of interest with regard to improving recombinant protein production in mammalian cells is through the use of lower temperature cultivation [12]. Mild hypothermic conditions result in prolonged generation time, maintenance of cell viability for longer periods, reduced glucose and glutamine consumption, suppressed release of waste products, delayed apoptosis, reduced protease activity and decreased $\mathrm{O}_{2}$ demand among others $[1,6,14]$. The overall effects, however, vary among cell lines, expression systems, and the product of interest, and opportunities exist for further enhancement of the cold shock effect on recombinant protein production in mammalian cells [12].

In the present study, we identified the mild-cold responsive element (MCRE) in the $5^{\prime}$ flanking region of the mouse cirp gene, which enhances gene expression at $32^{\circ} \mathrm{C}$ in cultured mammalian cells. We have found that Sp1 binds to the identified MCRE sequence, and that downregulation of $\mathrm{Sp} 1$ expression suppresses the induction of cirp gene expression at $32^{\circ} \mathrm{C}$. We have also shown that MCRE can be utilized to increase the yield of recombinant proteins produced in mammalian cells.

\section{Results}

Identification of the cis-regulatory element that enhances gene expression at $32^{\circ} \mathrm{C}$

To analyze the transcriptional regulation of cirp expression, we isolated an approximately $10 \mathrm{~kb}$-long $5^{\prime}$ genomic fragment upstream of the transcription start site. When we inserted the gene fragment spanning from position -970 to $+56(+1$ corresponds to the transcription start site) into the pcDNA5/FRT vector containing F-Luc cDNA without promoter and transfected NIH/3T3 Flp-In cells with this plasmid, the expression level of F-Luc mRNA was higher at $32^{\circ} \mathrm{C}$ than $37^{\circ} \mathrm{C}$, whereas there was not much difference in the degradation rate of mRNA at $37^{\circ} \mathrm{C}$ and $32^{\circ} \mathrm{C}$ (Figure $1 \mathrm{~A}$ ). Therefore, we made a series of constructs containing different $5^{\prime}$ deletions of the $-970 /+56$ fragment and tested their transcriptional activity by transiently transfecting HEK293 cells (Figure 1B). With the $-970 /+56$ fragment, higher expression of the reporter was observed at $32^{\circ} \mathrm{C}$ than $37^{\circ} \mathrm{C}$ as expected. When the $-340 /-220$ region was deleted from the $-340 /+56$ fragment, the transcriptional activity dropped more than 10-fold and the activity at $32^{\circ} \mathrm{C}$ became less than that at $37^{\circ} \mathrm{C}$. Negligible expression was observed without the $-120 /-1$ fragment, suggesting the presence of basal promoter activity within it. In order to determine the enhancer fragment responsible for the response to moderate cold, we subdivided the $-340 /-220$ fragment and tested each fragment for the enhancer activity using the SV40 minimal promoter. As shown in Figure $1 \mathrm{~B}$, the $-320 /-290$ and $-260 /-220$ fragments enhanced the expression more than twofold at $32^{\circ} \mathrm{C}$ relative to $37^{\circ} \mathrm{C}$. We noticed that the octanucleotide sequence $5^{\prime}$-TCCCCGCC-3' was common to both fragments (Figure 2A). When three copies of $5^{\prime}$-TTCCCCGCCG-3' 


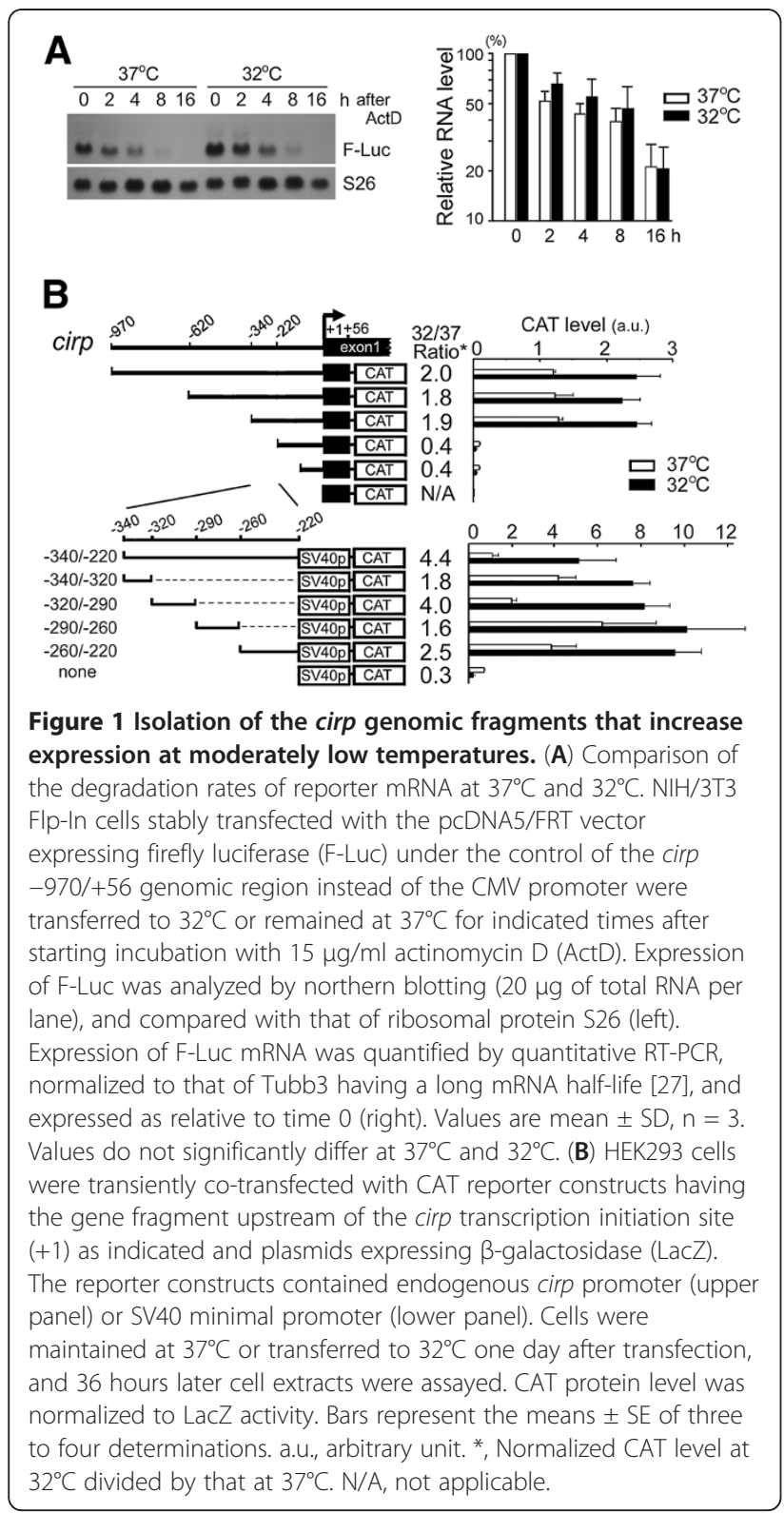

containing this octanucleotide were directly joined together and placed upstream of the SV40 promoter, the expression of CAT reporter was enhanced at $32^{\circ} \mathrm{C}$ as much as the cirp -340/-220 fragment (Figure 2B). Using the same expression constructs, we observed similar enhancing effects at $32^{\circ} \mathrm{C}$ in human U-2 OS cells, human HeLa cells, mouse NIH/3T3 cells, mouse BALB/3T3 cells and Chinese hamster $\mathrm{CHO}-\mathrm{K} 1$ cells as well. Thus, we named this octanucleotide sequence as the mild-cold responsive element (MCRE). The mutants of MCRE with a replacement of the first base $\mathrm{T}$ by $\mathrm{A}, \mathrm{G}$, or $\mathrm{C}$ showed similar enhancer activities to that of the wild type (Figure 2C). The second through $8^{\text {th }}$ bases, however, showed base preferences.

\section{A} -260 CAAATCAGCTGTĆ்́c்

B

\begin{tabular}{|c|c|c|c|}
\hline \multirow{2}{*}{ Enhancer } & \multicolumn{2}{|c|}{ CAT level (a.u.) } & \multirow{2}{*}{$\begin{array}{c}\text { Ratio** } \\
(32 / 37)\end{array}$} \\
\hline & $37^{\circ} \mathrm{C}$ & $32^{\circ} \mathrm{C}$ & \\
\hline ock & $0.68 \pm 0.01$ & $0.22 \pm 0.00$ & 0.33 \\
\hline SV40 & $1.37 \pm 0.01$ & $0.91 \pm 0.00$ & 0.66 \\
\hline MCREX3 & $1.60 \pm 0.01$ & $6.62 \pm 0.02$ & 4.13 \\
\hline irp -340/-220 & $1.46 \pm 0.02$ & $6.99 \pm 0.03$ & 4.79 \\
\hline
\end{tabular}

$\underline{\mathbf{C}}$

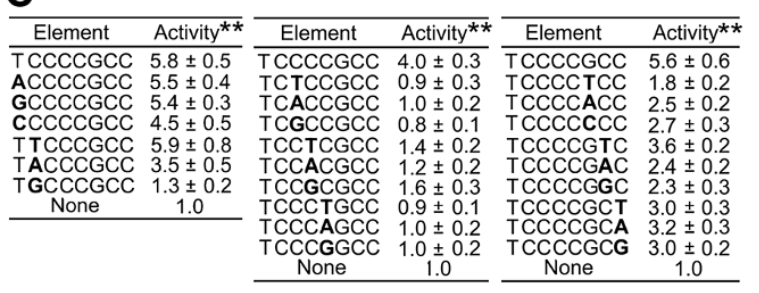

Figure 2 Identification of mild-cold responsive element (MCRE) in the cirp gene. (A) Sequence comparison of the cirp genomic fragments. Note the presence of common octanucleotide (bold). (B) Enhancer activity of MCRE. The indicated DNA fragments (Enhancer) were placed upstream of the SV40 promoter in PCAT promoter vector. HEK293 cells were co-transfected with the constructs and plasmids expressing $\beta$-galactosidase (LacZ). Cells were maintained at $37^{\circ} \mathrm{C}$ or transferred to $32^{\circ} \mathrm{C}$ on the following day, and 36 hours later cell extracts were assayed for CAT level and LacZ activity. Values are expressed as CAT protein level normalized to LacZ activity, and the means \pm SE of three determinations are shown. a.u., arbitrary unit. *, CAT level normalized to LacZ at $32^{\circ} \mathrm{C}$ divided by that at $37^{\circ} \mathrm{C}$. MCREx3, 3 copies of MCRE flanked on its $5^{\prime}$ and $3^{\prime}$ sides by $T$ and $G$, respectively, and joined together. (C) Activities of mutant MCRE. Three copies of the indicated octanucleotide (Element) each with a mutation (bold) were assayed for the activity as in (B). ${ }^{* *}$, normalized CAT level at $32^{\circ} \mathrm{C}$ divided by that at $37^{\circ} \mathrm{C}$, and expressed as relative to the value obtained with PCAT promoter vector having no enhancer (none). The means \pm SE of results from two independent transfections are shown.

Application of MCRE to recombinant protein production Various methods have been developed to increase the yield and reduce the production costs of recombinant proteins, and in many studies human secreted alkaline phosphatase (SEAP) is utilized as a model product $[15,16]$. To see if MCRE can be utilized to enhance the production of recombinant proteins in stably transfected mammalian cells, we directly connected 3 or 7 copies of $5^{\prime}$-TTCCCCGCCG-3' without spacer and placed them upstream of the CMV promoter in the pcDNA5/FRT vector expressing SEAP. Then, we transfected HEK293 Flp-In cells with the plasmids to generate stable transfectants. In contrast to the transient transfection experiments described above, the fold induction of SEAP expression at $32^{\circ} \mathrm{C}$ was not different with and without MCRE. When we used 48 copies of the MCRE and its active mutant ( $5^{\prime}$-TTCCCGCC-3', Figure 2C) as enhancers 
in CHO-K1 Flp-In cells, the amount of SEAP recovered was increased 6.6 -fold at $32^{\circ} \mathrm{C}$ compared with that at $37^{\circ} \mathrm{C}$ (Figure $3 \mathrm{~A}$ ). In the absence of the enhancer the increase was 3.0 -fold at $32^{\circ} \mathrm{C}$. Consistently, the SEAP mRNA level was 2.6-fold higher at $32^{\circ} \mathrm{C}$ compared with $37^{\circ} \mathrm{C}$ in the presence of the enhancer, but the levels were comparable at $32^{\circ} \mathrm{C}$ and $37^{\circ} \mathrm{C}$ in its absence (Figure 3B). As the basal level of expression at $37^{\circ} \mathrm{C}$ was also increased in the presence of the MCRE enhancer, the yield of SEAP obtained by culture at $32^{\circ} \mathrm{C}$ was 19.5-fold higher compared with the regular $37^{\circ} \mathrm{C}$ culture without the enhancer (Figure 3A). The MCRE enhancer was also effective in increasing the production of erythropoietin, a biotechnological protein, in $\mathrm{CHO}-\mathrm{K} 1$ cells (Figure $3 \mathrm{C}$ ). The enhancer effect was observed in U-2 OS cells as well (Figure 3D).

\section{Binding of Sp1 to MCRE}

To identify the proteins that bind to MCRE and regulate gene expression, the nucleotide sequence of the mouse cirp gene 5'-flanking region [NT_039500] was analyzed by using the Transcription Element Search System (TESS) [17]. Since TESS predicted that Sp1 binds to MCRE, we assessed binding of cellular Sp1 to MCRE by electrophoretic mobility shift assay (EMSA). Nuclear protein extracts from HeLa cells contained proteins that bound to the ${ }^{32} \mathrm{P}$-labelled MCRE probe in vitro (Figure $4 \mathrm{~A}$ ). The intensity of one of the bands was increased when cells were cultured at $32^{\circ} \mathrm{C}$ compared with those cultured at $37^{\circ} \mathrm{C}$, and could be competed out by a 50-fold molar excess of the unlabeled wild-type, but not mutant, probe indicating a specific interaction. The addition of anti-Sp1 antibody produced a supershift of the band, whereas the anti-Sp3 antibody had no effect. Western blot analysis demonstrated that the amount of Sp1 protein was increased (Figure 4B), and immunofluorescence microscopy showed that more Sp1 localized in the nucleus (Figure 4C) when cells were cultured at $32^{\circ} \mathrm{C}$.

To study whether Sp1 binds to MCRE in the cirp regulatory region in intact cells at $32^{\circ} \mathrm{C}$, we performed chromatin immunoprecipitation (ChIP) assays in BALB/ $3 \mathrm{~T} 3$ cells. We analyzed the $5^{\prime}$ upstream region containing MCRE and the first intron of the cirp gene. We detected about a 5-fold enhancement of Sp1 association with the MCRE region, but not with the intron region, at $32^{\circ} \mathrm{C}$ (Figure 4D). Although both $\mathrm{Sp} 1$ and $\mathrm{Sp} 3$ preferentially bind to similar DNA motifs, increased binding of $\mathrm{Sp} 3$ was not observed, suggesting that mild hypothermia specifically increases recruitment of $\mathrm{Sp} 1$ to the cirp regulatory region.

\section{Contribution of Sp1 to increased Cirp expression at $32^{\circ} \mathrm{C}$} The binding of more Sp1 to the cirp regulatory region does not necessarily imply that Sp1 is involved in the
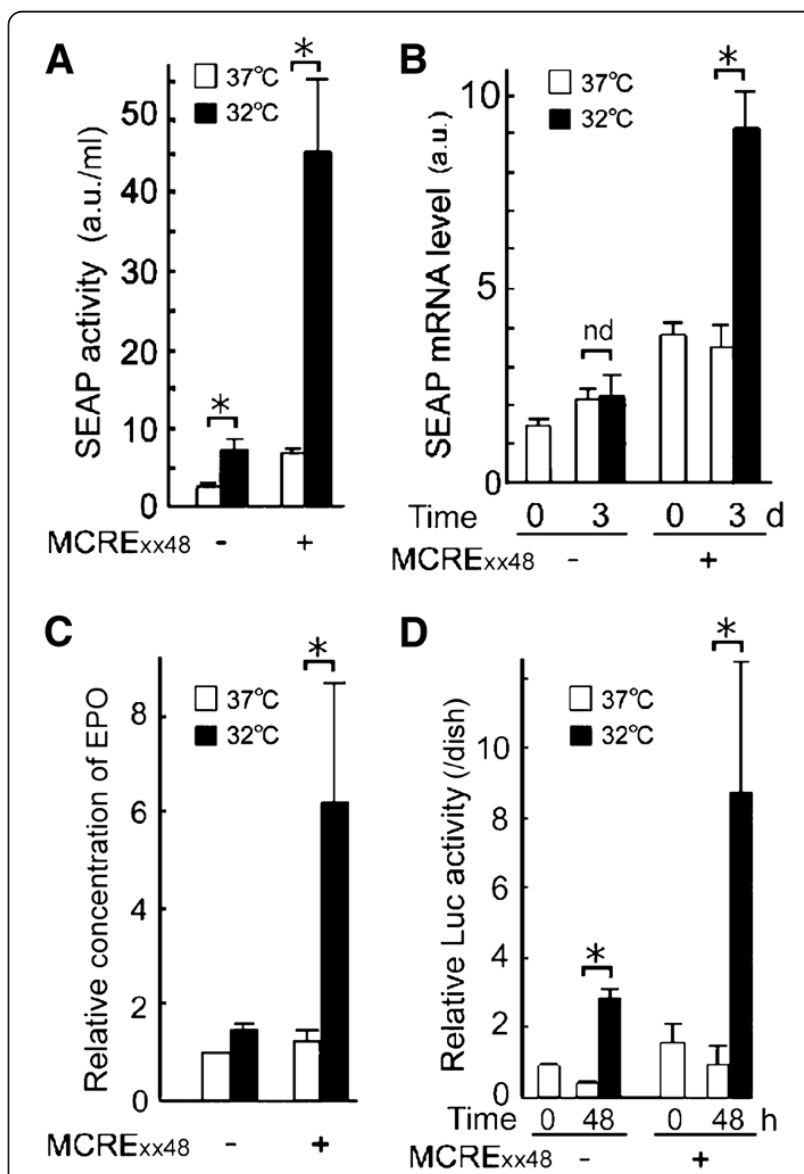

Figure 3 Enhancement of recombinant protein production at $32^{\circ} \mathrm{C}$ by MCRE. (A, B) CHO-K1 Flp-In cells were stably transfected with the pcDNA5/FRT vector expressing secreted alkaline phosphatase (SEAP) under the control of the CMV promoter with (+) or without (-) an enhancer containing 48 copies of MCRE and its active mutant (MCRExx48). Cells were cultured at $32^{\circ} \mathrm{C}$ or $37^{\circ} \mathrm{C}$ for 3 days, and the SEAP activity in culture media $(\mathbf{A})$ and mRNA levels in cells (B) were analyzed. SEAP mRNAs were quantified by quantitative RT-PCR, and expressed after normalization to those of $\beta$-actin. a.u., arbitrary unit. Values are mean \pm SE. nd, not different. * significantly different $(p<0.05)$. (C) CHO-K1 Flp-In cells were stably transfected with the pcDNA5/FRT vector expressing erythropoietin (EPO) under the control of the CMV promoter with $(+)$ or without $(-)$ the MCRExx48 enhancer. Cells were cultured at $32^{\circ} \mathrm{C}$ or $37^{\circ} \mathrm{C}$ for 3 days, and the EPO concentration in culture media was determined. Values are expressed as relative to the value obtained in cells transfected with plasmids having CMV promoter alone (-) and cultured at $37^{\circ} \mathrm{C}$. (D) U-2 OS Flp-In cells were stably transfected with the indicated pcDNA5/FRT vector expressing firefly luciferase (Luc) under the control of the CMV promoter with (+) or without (-) MCRExx48. Cells were transferred to $32^{\circ} \mathrm{C}$ or remained at $37^{\circ} \mathrm{C}$ for indicated times. Cell extracts were assayed for Luc activity and normalized to the protein level. Values are expressed as relative to the value obtained in cells transfected with plasmids having CMV promoter alone $(-)$ at time 0 , and mean \pm SE. Experiments were repeated twice $(\mathbf{A}, \mathbf{B})$ and three times $(\mathbf{C}, \mathbf{D})$, with similar results. 


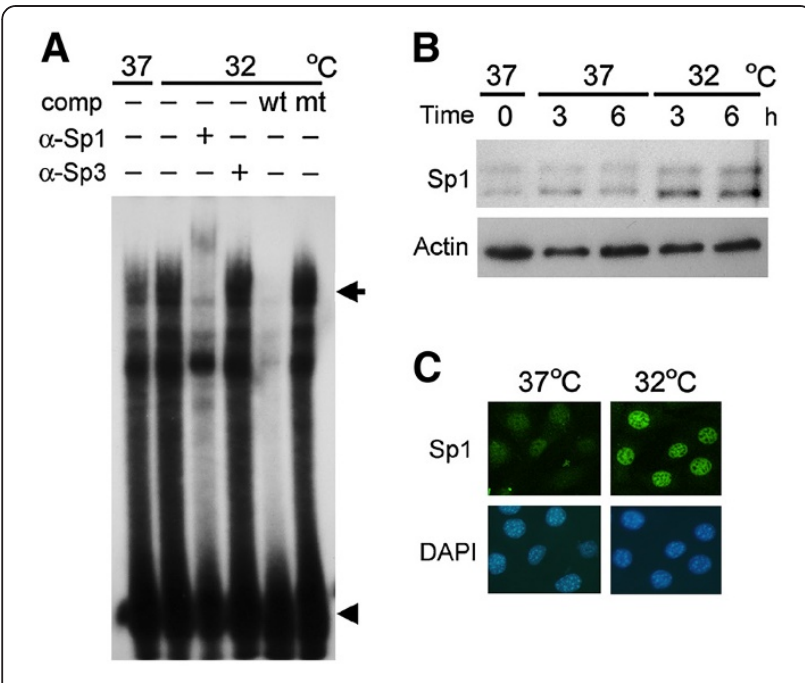

D

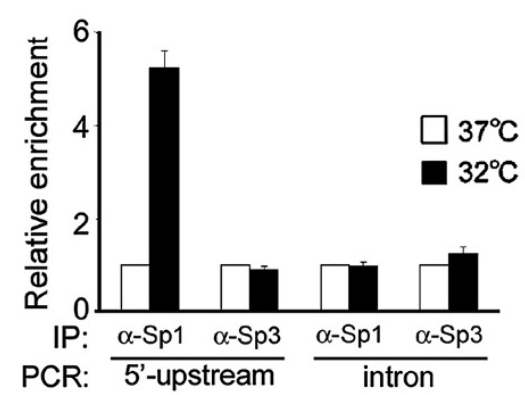

Figure 4 Recruitment of Sp1 to the cirp regulatory region at $32^{\circ} \mathbf{C}$. HeLa cells $(\mathbf{A})$ and BALB/3T3 cells (B-D) were cultured at $37^{\circ} \mathrm{C}$, transferred to $32^{\circ} \mathrm{C}$ or remained at $37^{\circ} \mathrm{C}$ for 6 hours or indicated times, and then analyzed. (A) EMSA analysis of nuclear extracts using ${ }^{32}$ p-labeled MCRE oligonucleotide as a probe. comp, competition with a 50-fold molar excess of unlabeled wild-type (wt) or mutant $(\mathrm{mt})$ probe. $(+)$ and $(-)$, present and absent, respectively. Arrow, specific probe-protein complex. Arrowhead, free probe. (B) Western blotting. Cell lysates were prepared at the indicated times, and analyzed using anti-Sp1 and anti-actin antibodies. (C)

Immunofluorescence staining of cells. Sp1 was detected with anti-Sp1 antibody and FITC-conjugated anti-mouse lgG, and appears green under the confocal microscope. Nuclei were stained with DAPI, and appear blue. (D) ChIP assays. qPCR analysis for the $5^{\prime}$ upstream region containing MCRE and the first intron of the cirp gene using chromatins pulled down with anti-Sp1 antibody or anti-Sp3 antibody from cells incubated at the indicated temperatures. The amount of precipitated DNA relative to input (percent of input) was determined for each sample. Values are expressed as relative to those obtained in cells cultured at $37^{\circ} \mathrm{C}$. Standard deviations from triplicate PCR reactions are indicated. Experiments were repeated three $(\mathbf{A}, \mathbf{B})$ or four $(\mathbf{C}, \mathbf{D})$ times, with similar results.

induction of cirp expression in response to moderately low temperatures. To confirm this, we first analyzed the effects of Sp1 expression on the endogenous Cirp expression. As shown in Figure 5A, overexpression of Sp1 further increased the Cirp protein levels after transferring the cells to $32^{\circ} \mathrm{C}$. Conversely, downregulation of Sp1 by

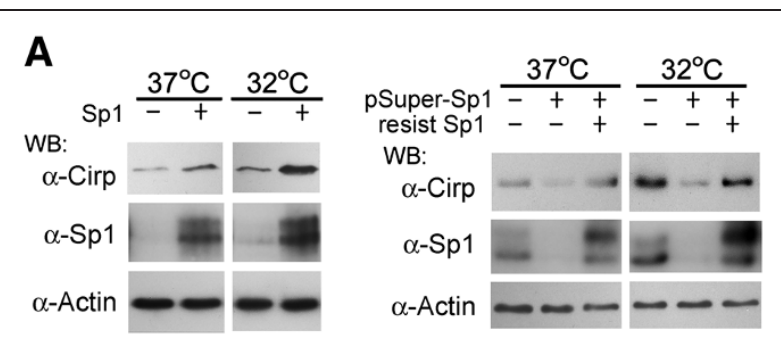

B

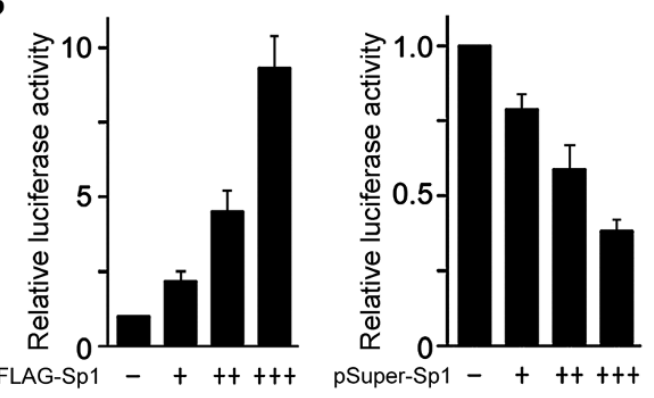

Figure 5 Contribution of Sp1 to increased expression at $32^{\circ} \mathrm{C}$. (A) Effects of Sp1 on endogenous cirp expression. U-2 OS (left) and HEK293 (right) cells were transfected with plasmids expressing Sp1 or shRNA for Sp1 (pSuper-Sp1) as indicated, and one day later transferred to $32^{\circ} \mathrm{C}$ or remained at $37^{\circ} \mathrm{C}$. Six hours after the transfer, cell lysates were analyzed by western blotting using anti-Cirp, anti-Sp1 and anti-actin antibodies. In some experiments, plasmids expressing wild-type Sp1 protein from pSuper-Sp1-resistant mRNA (resist Sp1) were also co-transfected. (-), transfection with empty vector. (+), transfection with the indicated plasmids. Experiments were repeated three (left) or four (right) times, with similar results. (B) Effects on reporter gene expression. HEK293 cells were co-transfected with the F-Luc reporter plasmids driven by the wild-type $-500 /+56$ cirp fragment, pRL-TK, and increasing amounts (+ to +++ ) of plasmids expressing FLAG-tagged Sp1 (FLAG-Sp1) or pSuper-Sp1 as indicated. One day after transfection, cells were transferred to $32^{\circ} \mathrm{C}$ or remained at $37^{\circ} \mathrm{C}$. Twenty-four hours later, luciferase activities were analyzed. F-Luc activity was normalized to R-Luc activity and expressed as relative to the value obtained in cells co-transfected with the reporter, pRL-TK, and empty vector (-). Values are mean \pm SE of triplicates, $n=3$.

shRNA decreased the Cirp protein levels, and the induction of Cirp at $32^{\circ} \mathrm{C}$ became less prominent. Rescue of the effects of shRNA by expression of an shRNAresistant mRNA for wild-type Sp1 indicted that the observed changes were not due to the off-target effects.

The reporter assays further demonstrated that overexpression of Sp1 dose-dependently increased the transcriptional activity of the cirp upstream region containing MCRE, whereas downregulation of Sp1 expression suppressed it (Figure 5B).

When MCRE sequences were mutated in the reporter constructs, the enhancement of the reporter gene expression by $\mathrm{Sp} 1$ overexpression became minimal (Figure 6A), and the suppressive effects of $\mathrm{Sp} 1$ downregulation were not observed (Figure 6B). These results indicate that the 


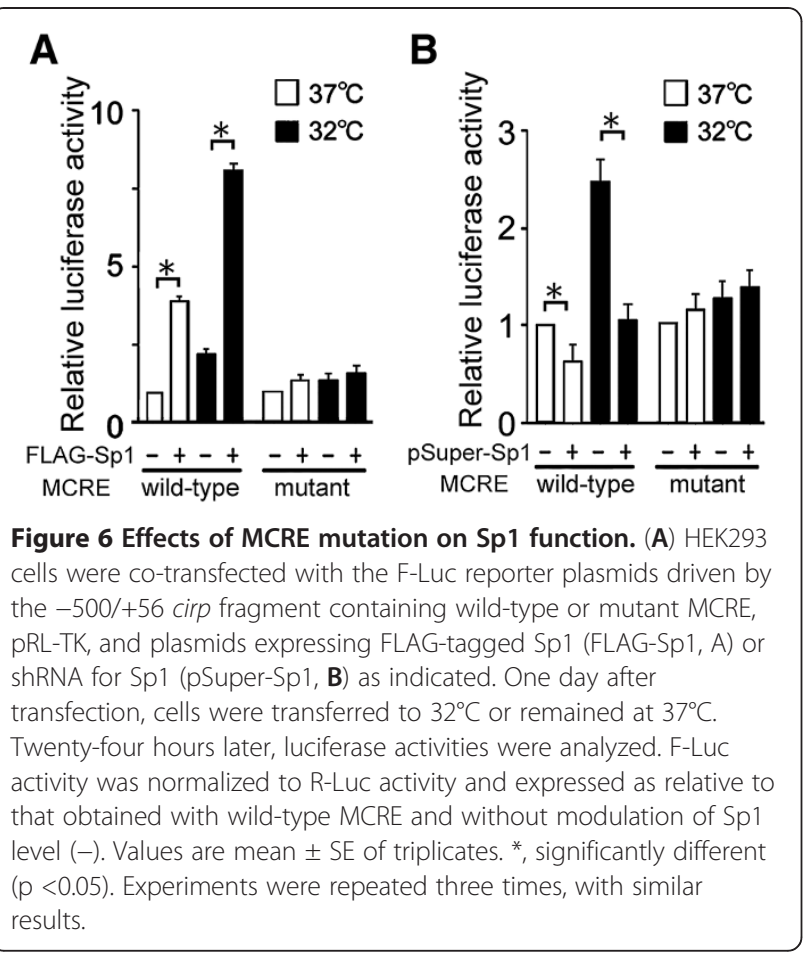

effects of Sp1 are mediated by its interaction with the MCRE.

\section{Discussion}

We and others have previously reported that the half-life of cirp mRNAs is only marginally influenced by temperature down-shift $[2,18]$. Consistent with a notion that the transcription rate of cirp is increased at moderately low temperatures, we have herein identified a MCRE in the $5^{\prime}$ flanking region of the cirp gene that enhances gene expression at $32^{\circ} \mathrm{C}$. We further demonstrated that $\mathrm{Sp} 1$ binds to MCRE, and that more Sp1 is localized in the nucleus at $32^{\circ} \mathrm{C}$ to bind to the genomic region containing MCRE. In addition, the reporter assays with mutant MCRE and modulation of the Sp1 expression level showed that the expression of cirp is dependent, at least partly, on Sp1 and MCRE and that Sp1 contributes to the cold shock response at $32^{\circ} \mathrm{C}$.

Cis-regulatory elements like enhancers and promoters are usually characterized by reporter gene assays in cultured cell lines [19]. We did the transient reporter gene assays using HEK293 cells, and identified the MCRE. Although present in two different genomic fragments of cirp with enhancer activity, mutagenesis experiments of the identified MCRE octanucleotide revealed that the first base could vary. Furthermore, the binding sequences of Sp1 predicted by TESS in the cirp genome did not include the first base of the MCRE, suggesting that the actual element might be the heptanucleotide $5^{\prime}$-CCCCGCC-3'.
The cold-responsive enhancer activity of MCRE was consistently observed when various cell lines including HEK293 and CHO-K1 cells were transiently transfected. In cells stably transfected with similar MCRE constructs, however, the cold-inducible enhancer activity was difficult to observe. This result may not be so surprising because transient reporter gene assays are often a poor proxy for the activities of regulatory elements integrated in the genome, which can be active in narrow windows of development, differentiation and cellular conditions [20]. How the presence of many copies of MCRE seemingly circumvented the problem has yet to be clarified. Although many studies have suggested that recombinant protein production can be increased by culturing at subphysiological temperatures [12], low temperature also causes growth arrest of cells and suppression of gene expression in general, resulting in variable yields. Thus, specific enhancement of the target gene transcription at $32^{\circ} \mathrm{C}$ by using MCRE is a promising method to increase the final yield of recombinant proteins in various cell lines. Interestingly, Thaisuchat et al. [21] have recently identified a novel temperature sensitive promoter (222 bp long) in the S100a6 (calcyclin) gene, which comprises two Sp1 sites.

Sp1 binds GC-rich motifs with high affinity and can regulate the expression of TATA-containing and TATAless genes via multiple mechanisms $[10,11,22]$. Sp1 generally activates gene transcription, whereas $\mathrm{Sp} 3$ has both transcriptional repressor and activating properties. Discher et al. [23] showed by transient transfection that hypoxia enhances the expression of a reporter gene directed by the pyruvate kinase $\mathrm{M}$ promoter in myocytes. The hypoxia response was localized to a conserved GC-rich element that bound Sp1 and Sp3. Hypoxia induced gene expression because it caused depletion of $\mathrm{Sp} 3$, removing its transcriptional repression, whereas Sp1 levels remained unchanged. This is unlikely the case with the cirp gene, as the western blotting and ChIP assays demonstrated that more $\mathrm{Sp} 1$ bound to the chromatin region containing $\mathrm{MCRE}$ at $32^{\circ} \mathrm{C}$ than $37^{\circ} \mathrm{C}$, whereas the level of chromatin-bound Sp3 did not differ between these temperatures.

Although $\mathrm{Sp} 1$ was once thought to serve mainly as a constitutive activator of housekeeping genes, growing evidence indicates that posttranslational modifications such as phosphorylation, acetylation, sumoylation, ubiquitylation and glycosylation can influence the transcriptional activity and stability of Sp1 [10,22]. For example, Sp1 is phosphorylated at Ser101 by ataxia telangiectasia mutated kinase in response to DNA damage, and the proportion of chromatin-bound phosphorylated Sp1 rapidly increases [24]. Thus, to clarify the molecular mechanisms underlying the observed increase in the amount of $\mathrm{Sp} 1$ in the nucleus at $32^{\circ} \mathrm{C}$, modifications of $\mathrm{Sp} 1$ should 
be analyzed. Furthermore, Sp1 can regulate the expression of genes via interactions or interplay with other transcription factors such as Ets-1, c-myc, c-Jun and Egr-1, and/or components of the basal transcriptional machinery, and has been linked to chromatin remodeling through interactions with p300 and histone deacetylases [22]. The factors collaborating or competing with ubiquitously expressed Sp1 should be identified to clarify the underlying mechanism of cirp induction at moderately low temperatures.

\section{Conclusions}

A novel enhancer element, MCRE, that promotes gene expression 3- to 7-fold in various cell lines upon a temperature shift to $32^{\circ} \mathrm{C}$ is described. In combination with moderately low culture temperatures, MCRE can be utilized in transient as well as stable transfection to produce large amounts of proteins in a short period of time. By binding Sp1, MCRE contributes to the induction of cirp at $32^{\circ} \mathrm{C}$. Elucidating the molecular mechanisms of the cold shock response will help develop novel strategies for the treatment of diseases involving cold shock proteins such as male infertility and cancers, and for the production of a variety of diagnostically and therapeutically useful recombinant proteins.

\section{Methods}

\section{Cell culture}

Cells were cultured in Dulbecco's modified Eagle's medium supplemented with $10 \%$ fetal bovine serum (HEK293 cells, U-2 OS cells, and HeLa cells) or calf serum (BALB/3T3 cells and NIH/3T3 cells), or $\alpha$ medium supplemented with $10 \%$ fetal bovine serum (CHO-K1 cells) at $37^{\circ} \mathrm{C}$ or $32^{\circ} \mathrm{C}$ in a $5 \% \mathrm{CO}_{2}$ humidified atmosphere. To produce isogenic stable cell lines, the Flp-In System (Life Technologies) was used. Cells were first transfected with pFRT/lacZeo to generate the Flp-In host cell lines. The calcium phosphate method was used to transfect cells with plasmid DNA as described [25].

\section{DNA constructs and reporter gene assays}

The mouse cirp gene spanning about $10 \mathrm{~kb}$ upstream of the transcription start site to $56 \mathrm{bp}$ downstream of it was cloned into pBluescript SK(-) (Stratagene). Fragments from this were subcloned into pCAT-Basic or PCAT promoter vectors (Promega). The $-500 /+56$ cirp genomic fragment containing mutant MCRE (5'-TCCAAGCC-3') was generated with the Quick-Change site-directed mutagenesis kit (Stratagene). FLAG-tagged Sp1 was expressed by cloning the coding sequence of Sp1 cDNA ([NM_013672] for mouse and [NM_138473] for human) into the pCMV-3Tag-1 vector (Agilent Technologies). Human Sp1 cDNA was also cloned into the pcDNA3 vector (Invitrogen) and expressed without a tag. For Sp1 protein knockdown, pSuper-Sp1 plasmid was engineered as described [25], with the $\mathrm{Sp} 1$ target sequence: $5^{\prime}$-CCTGCAGCAGAATTGAGTC- $3^{\prime}$ for mouse, and 5'-GAATCGCACA GTCTCTGGT-3' for human. To express wild-type $\mathrm{Sp} 1$ protein from mRNA resistant to pSuper-Sp1, the human Sp1 cDNA coding sequence was silently mutated at the target sequence to $5^{\prime}$-GAATAGAACA GTCAGTGGT-3' (mutations underlined), and cloned into the pCMV-3Tag-1 vector.

One day after co-transfection with the pCAT-Basic or pCAT promoter vector-based constructs and CDM8LacZ, the cells were divided into two groups. One is transferred to $32^{\circ} \mathrm{C}$ and the other remained at $37^{\circ} \mathrm{C}$. Thirty six hours later, cell lysates were prepared and the amount of chloramphenicol acetyltransferase (CAT) protein and $\beta$-galactosidase activity were determined using CAT ELISA kit (Roche Diagnostic) and $\beta$-galactosidase assay kit (Stratagene), respectively.

To assess the enhancer activity in stably transfected cells, the DNA fragment of interest was placed upstream of the CMV promoter in the pcDNA5/FRT vector (Life Technologies) expressing SEAP or human erythropoietin [NM_000799]. In some experiments, the DNA fragment containing 48 copies of the sequence $5^{\prime}$ TTCCCCGCCGCGTTTCCCGCCG-3' flanked by NotI and $\mathrm{Xba \textrm {I }}$ recognition sequences (MCRExx48) was used as an enhancer. Flp-In host cell lines were co-transfected with the constructed plasmids and pOG44 (Life Technologies), and the stable transfectants were selected with hygromycin. SEAP activities were assayed as described [26]. Erythropoietin concentrations in cell culture supernatant were measured with the EPO ELISA kit (Roche Diganostics Japan).

For luciferase reporter assays, the firefly luciferase (F-Luc) reporter plasmids driven by the $-500 /+56$ cirp genomic fragment containing wild-type or mutant MCRE were constructed and used with the Sp1 expression plasmids, pSuper-Sp1 plasmids or the corresponding empty vectors. The pRL-TK (Promega), carrying the Renilla luciferase (R-Luc) under the control of the thymidine kinase promoter, was also used in co-transfection. Cultures were continued at $37^{\circ} \mathrm{C}$ for 24 hours after transfection, and then transferred to $32^{\circ} \mathrm{C}$ or remained at $37^{\circ} \mathrm{C}$. Twenty-four hours later, cells were harvested and luciferase activities were analyzed using the Dual-Luciferase assay kit (Promega).

Experiments were repeated two to four times, and results were assessed for statistical significance by Student's $t$ test using the JMP statistical software package (SAS Institute Inc.).

\section{ChIP assay}

ChIP assay was performed using the ChIP-IT Express Enzymatic kit (Active Motif) following the manufacturer's 
instructions. Briefly, cells were fixed with formaldehyde, lysed, and the nuclei were incubated in Enzymatic Shearing Cocktail. For each immunoprecipitation, $10 \mu \mathrm{g}$ of sheared chromatin were incubated overnight at $4^{\circ} \mathrm{C}$ with $2 \mu \mathrm{g}$ of normal rabbit IgG, or the corresponding antibodies against Sp1 (sc-14027, Santa Cruz), Sp3 (sc-10252, Santa Cruz), RNA polymerase II (sc-899, Santa Cruz), or normal rabbit IgG (Santa Cruz) and protein G magnetic beads. Anti-RNA polymerase II antibody and IgG were used as positive and negative controls, respectively. Following immunoprecipitation, the cross-linking was reversed by incubation in $0.1 \mathrm{M} \mathrm{NaCl}$ for 2 hours at $65^{\circ} \mathrm{C}$ followed by proteinase- $\mathrm{K}$ treatment for 1 hour at $37^{\circ} \mathrm{C}$. qPCR was used to determine the amount of precipitated DNA relative to input as (Amount of ChIP DNA)/(Amount of input DNA), and the results were expressed as relative to the value at $37^{\circ} \mathrm{C}$. qPCR was performed using ABI-PRISM 7000 (Applied Biosystems) and the SYBR Premix Ex Taq Kit (Takara Bio) with primers for cirp $5^{\prime}$ upstream region (-376/-173) (5'-GTCGATGAGTCAAGGTTGGAGCC-3' and $5^{\prime}$-GTTTTGATTGGCTGGAATCTTTCC-3') and cirp intron $(+978 /+1153)\left(5^{\prime}\right.$-CAGGTGTAATCAAGACCTA GAATC-3' and 5'-AGTTGGAGGCAAAGGAACAGAATC-3'). This cirp intron sequence contains no potential Sp1binding site as assessed with TESS. PCR conditions: $96^{\circ} \mathrm{C}$ for 2 minutes; 50 cycles of $96^{\circ} \mathrm{C}$ for 10 seconds, $57^{\circ} \mathrm{C}$ for 20 seconds, and $72^{\circ} \mathrm{C}$ for 31 seconds; $72^{\circ} \mathrm{C}$ for $10 \mathrm{~min}-$ utes; followed by a post-PCR dissociation curve analysis. Input represents the $0.1 \%$ of total pre-immunoprecipitated chromatin. We analyzed 4 independent ChIPs, each in triplicate qPCRs.

\section{Analyses of gene expression}

For RT-qPCR analysis, total RNA was isolated and first-strand cDNA was prepared as described previously [25]. qPCR was performed with primers for SEAP (5'-CTCCAACATGGACATTGACG-3' and $5^{\prime}$-CCCACC TTGGCTGTAGTCAT-3'), $\beta$-actin (5/-AGAGGGAAATT GTGCGTGAC-3' and $5^{\prime}$-TCTCCAGGGAGGAAGAGGAT-3), F-Luc (5'-TGTGGACGAAGTACCGAAAGGT-3' ${ }^{\prime}$ and $5^{\prime}$ CCTTCTTGGCCTTTATGAGGATCT-3'), and tubulin, beta3 class III (Tubb3) (5'-CTTTTCGTCTCTAGCCGCGT-3' and $5^{\prime}$-CTCATCGCTGATGACCTCCC-3). Tubb3 mRNA is known to have a long half-life [27]. The real-time PCRs were set up according to the manufacturer's instructions (SYBR Premix Ex Taq Kit, Takara Bio). PCR conditions: $95^{\circ} \mathrm{C}$ for 10 seconds; 41 cycles of $95^{\circ} \mathrm{C}$ for 5 seconds and $60^{\circ} \mathrm{C}$ for 34 seconds, followed by a post-PCR dissociation curve analysis. To check the size and specificity of the reaction, $\mathrm{PCR}$ products were run on agarose gels, stained with ethidium bromide, and photographed under UV light. In some experiments, PCR products were extracted from the gels, cloned by TA cloning, and their DNA sequences were verified.
Western blotting and immunofluorescence microscopy were performed as described [2,9] using anti-Cirp, antiFLAG, anti- $\beta$ actin, anti-Sp1, and FITC-conjugated antirabbit immunoglobulin (Dako) antibodies. RNAs were isolated from cells using. ISOGENE (Nippon Gene), and northern blotting was performed as described [2].

\section{Nuclear extracts and EMSA}

Extraction of nuclear proteins and EMSA were performed essentially as described [25]. ${ }^{32} \mathrm{P}$-labeled double stranded oligonucleotide (5'-TCAGCTGTCCCCGCCTCC TAGT-3') was used as a probe. For competition and supershift experiments, proteins were preincubated with the unlabeled probe, its mutant $\left(5^{\prime}\right.$ - TCAGCTGTCCAA GCCTCCTAGT-3'), the anti-Sp1 antibody or anti-Sp3 antibody for 1 hour at $4^{\circ} \mathrm{C}$. Labeled probes were then added, and the reaction tubes were incubated for $30 \mathrm{~min}$ at room temperature.

\section{Abbreviations}

CAT: Chloramphenicol acetyltransferase; ChIP: Chromatin immunoprecipitation; Cirp: Cold-inducible RNA-binding protein; EMSA: Electrophoretic mobility shift assay; F-Luc: Firefly luciferase: MCRE: Mild-cold responsive element; Rbm3: RNA binding motif protein 3; R-Luc: Renilla luciferase; SEAP: Secreted alkaline phosphatase; Sp1: Specificity protein 1; TESS: Transcription Element Search System.

\section{Competing interests}

The authors declare that they have no competing interests.

\section{Authors' contributions}

YS carried out the molecular genetic studies and drafted the manuscript. $\mathrm{HirH}$ participated in the design of the study and performed the molecular analysis. HisH carried out the molecular and cellular biological studies.YL carried out the molecular genetic studies. TF participated in the design of the study and performed the statistical analysis. TS carried out the molecular biological studies. MMC carried out the molecular biological studies and helped to draft the manuscript. Kl participated in the design of the probes and sequence analysis. TC participated in study design and coordination. JF conceived of the study, carried out the reporter gene assays, and participated in its design and coordination and helped to draft the manuscript. All authors read and approved the final manuscript.

\section{Acknowledgements}

We thank Prof. R.J. Mayer, University of Nottingham, U.K. for reading the manuscript. This work was partly supported by Grants-in-Aid for Scientific Research (KAKENHI) from the Japan Society for the Promotion of Science, a grant from the Smoking Research Foundation of Japan, and the Cooperative Research Project Program at Institute of Development, Aging and Cancer, Tohoku University.

\section{Author details}

${ }^{1}$ Department of Clinical Molecular Biology, Graduate School of Medicine, Kyoto University, 54 Shogoin Kawaharacho, Sakyo-ku, Kyoto 606-8507, Japan. 2Department of Gastroenterology and Hepatology, Graduate School of Medicine, Kyoto University, Kyoto, 606-8507, Japan. ${ }^{3}$ Current address: Department of Gastroenterology and Hepatology, Kobe City Medical, Center West Hospital, Kobe 653-0013, Japan. ${ }^{4}$ Department of Gastroenterology and Hepatology, Kinki University School of Medicine, Osaka 589-8511, Japan. ${ }^{5}$ Current address: Department of Bioimaging and Cell Signaling, Graduate School of Biostudies, Kyoto University, Kyoto 606-8501, Japan. 
References

1. Fujita J: Cold shock response in mammalian cells. J Mol Microbiol Biotechnol 1999, 1:243-255

2. Nishiyama H, Itoh $\mathrm{K}$, Kaneko $Y$, Kishishita M, Yoshida O, Fujita J: A glycinerich RNA-binding protein mediating cold-inducible suppression of mammalian cell growth. J Cell Biol 1979, 137:899-908.

3. Yang C, Carrier F: The UV-inducible RNA-binding protein A18 (A18 hnRNP) plays a protective role in the genotoxic stress response. $J$ Biol Chem 2001, 276:47277-47284

4. Wellmann S, Bührer C, Moderegger E, Zelmer A, Kirschner R, Koehne $\mathrm{P}$, Fujita J, Seeger K: Oxygen-regulated expression of the RNA-binding proteins RBM3 and CIRP by a HIF-1-independent mechanism. J Cell SC 2004, 117:1785-1794.

5. De Leeuw F, Zhang T, Wauquier C, Huez G, Kruys V, Gueydan C: The coldinducible RNA-binding protein migrates from the nucleus to cytoplasmic stress granules by a methylation-dependent mechanism and acts as a translational repressor. Exp Cell Res 2007, 313:4130-4144.

6. Sakurai T, Itoh K, Higashitsuji H, Nonoguchi K, Liu Y, Watanabe H, Nakano T, Fukumoto M, Chiba T, Fujita J: Cirp protects against tumor necrosis factoralpha-induced apoptosis via activation of extracellular signal-regulated kinase. Biochim Biophys Acta 2006, 1763:290-295.

7. Zeng Y, Kulkarni P, Inoue T, Getzenberg RH: Down-regulating cold shock protein genes impairs cancer cell survival and enhances chemosensitivity. J Cell Biochem 2009, 107:179-188.

8. Artero-Castro A, Callejas FB, Castellvi J, Kondoh H, Carnero A, FernándezMarcos PJ, Serrano M, Ramón y Cajal S, Lleonart ME: Cold-inducible RNAbinding protein bypasses replicative senescence in primary cells through extracellular signal-regulated kinase 1 and 2 activation. Mol Cell Biol 2009, 29:1855-1868

9. Masuda T, Itoh K, Higashitsuji H, Higashitsuji H, Nakazawa N, Sakurai T, Liu Y, Tokuchi H, Fujita T, Zhao Y, Nishiyama H, Tanaka T, Fukumoto M, Ikawa M, Okabe M, Fujita J: The cold-inducible RNA-binding protein Cirp interacts with Dyrk1b/Mirk and promotes proliferation of immature male germ cells in mice. Proc Natl Acad Sci U S A 2012, 109:10885-10890.

10. Archer MC: Role of sp transcription factors in the regulation of cancer cell metabolism. Genes Cancer 2011, 2:712-719.

11. Wierstra I: Sp1: emerging roles-beyond constitutive activation of TATA-less housekeeping genes. Biochem Biophys Res Commun 2008, 372:1-13.

12. Al-Fageeh MB, Marchant RJ, Carden MJ, Smales CM: The cold-shock response in cultured mammalian cells: harnessing the response for the improvement of recombinant protein production. Biotechnol Bioeng 2006, 93:829-835.

13. Mohan C, Kim YG, Koo J, Lee GM: Assessment of cell engineering strategies for improved therapeutic protein production in $\mathrm{CHO}$ cells. Biotechnol J 2008, 3:624-630.

14. Yoon SK, Song JY, Lee GM: Effect of low culture temperature on specific productivity, transcription level, and heterogeneity of erythropoietin in Chinese hamster ovary cells. Biotechnol Bioeng 2003, 82:289-298.

15. Park KS, Seol W, Yang HY, Lee SI, Kim SK, Kwon RJ, Kim EJ, Roh YH, Seong BL, Kim JS: Identification and use of zinc finger transcription factors that increase production of recombinant proteins in yeast and mammalian cells. Biotechnol Prog 2005, 21:664-670.

16. Becerra-Arteaga A, Mason HS, Shuler ML: Production, secretion, and stability of human secreted alkaline phosphatase in tobacco NT1 cell suspension cultures. Biotechnol Prog 2006, 22:1643-1649.

17. TESS: Transcription Element Search System. [http://www.cbil.upenn.edu/cgibin/tess/tess].

18. Al-Fageeh MB, Smales CM: Cold-inducible RNA binding protein (CIRP) expression is modulated by alternative mRNAs. RNA 2009, 15:1164-1176.

19. Iwata T, Minucci S, McGowan M, Carper D: Identification of a novel ciselement required for the constitutive activity and osmotic response of the rat aldose reductase promoter. J Biol Chem 1997, 272:32500-32506.

20. Bulger M, Groudine M: Functional and mechanistic diversity of distal transcription enhancers. Cell 2011, 144:327-339.

21. Thaisuchat $H$, Baumann M, Pontiller J, Hesse F, Ernst W: Identification of a novel temperature sensitive promoter in CHO cells. BMC Biotechnol 2011 11:51.

22. Tan NY, Khachigian LM: Sp1 phosphorylation and its regulation of gene transcription. Mol Cell Biol 2009 , 29:2483-2488.
23. Discher DJ, Bishopric NH, Wu X, Peterson CA, Webster KA: Hypoxia regulates beta-enolase and pyruvate kinase-M promoters by modulating Sp1/Sp3 binding to a conserved GC element. J Biol Chem 1998, 273:26087-26093.

24. Iwahori S, Yasui Y, Kudoh A, Sato Y, Nakayama S, Murata T, Isomura H, Tsurumi T: Identification of phosphorylation sites on transcription factor $\mathrm{Sp} 1$ in response to DNA damage and its accumulation at damaged sites. Cell Signal 2008, 20:1795-1803.

25. Higashitsuji H, Higashitsuji H, Nagao T, Nonoguchi K, Fujii S, Itoh K, Fujita J: A novel protein overexpressed in hepatoma accelerates export of NF-kappa B from the nucleus and inhibits p53-dependent apoptosis. Cancer Cell 2002, 2:335-346.

26. Cullen BR, Malim MH: Secreted placental alkaline phosphatase as a eukaryotic reporter gene. Methods Enzymol 1992, 216:362-368

27. Sharova LV, Sharov AA, Nedorezov T, Piao Y, Shaik N, Ko MS: Database for mRNA half-life of 19977 genes obtained by DNA microarray analysis of pluripotent and differentiating mouse embryonic stem cells. DNA Res 2009, 16:45-58.

doi:10.1186/1472-6750-12-72

Cite this article as: Sumitomo et al:: Identification of a novel enhancer that binds Sp1 and contributes to induction of cold-inducible RNAbinding protein (cirp) expression in mammalian cells. BMC Biotechnology 2012 12:72

\section{Submit your next manuscript to BioMed Central and take full advantage of:}

- Convenient online submission

- Thorough peer review

- No space constraints or color figure charges

- Immediate publication on acceptance

- Inclusion in PubMed, CAS, Scopus and Google Scholar

- Research which is freely available for redistribution 